Bernaerts, M. J. \& De Ley, J. (1960). J. gen. Microbiol. 22, 129-136

\title{
Microbiological Formation and Preparation of 3-Ketoglycosides from Disaccharides
}

\author{
BY M. J. BERNAERTS \\ Central Laboratory, Ministry of Economic Affairs, Brussels, Belgium \\ AND J. DE LEY \\ Biochemical Laboratory, Veterinary College, State University, Ghent, Belgium
}

SUMMARY: The conditions for the formation, the isolation and the purification of a new class of disaccharide derivatives, namely 3-ketoglycosides, are described. These compounds are formed by the action of certain bacteria, provisionally called Alcaligenes faecalis, on lactose, maltose, lacto- or maltobionate. From lactose about $75 \%$ of the total amount was converted into the corresponding 3-ketoglycoside. Neither the corresponding monoses, gluconate nor equimolar mixtures of these substances were oxidized this way. The new substances were ultimately purified by paper chromatography. No crystalline preparations have so far been obtained. These bacteria contain strong hydrolases for either maltose or lactose, and weak ones for the bionates. The yield of 3-ketoglycosides is inversely proportional to the hydrolase activity.

The first step in the catabolism of disaccharides by most tissues is usually performed by a transferase, such that a hexose moiety is linked to another sugar-acceptor. Hydrolysis is a special case of this general rule, water being the acceptor. Bacteria are notable for effecting other types of disaccharide breakdown: Pseudomonas saccharophila utilizes sucrose after the action of sucrose phosphorylase, and several strains of the genus Pseudomonas (Stodola \& Lockwood, 1947; Kluyver, De Ley \& Rijven, 1951) and other bacteria (Eddy, 1958), are able to oxidize lactose and maltose to the corresponding bionic acids. The latter compounds can be hydrolysed by the corresponding $\beta$-galactosidase and $\alpha$-glucosidase of several bacteria. One example was studied in Corynebacterium simplex (Bernaerts \& De Ley, 1957).

We have found still another mechanism for disaccharide breakdown. It consists in the primary formation of a 3-keto-glycoside without splitting of the oxygen bridge. These compounds are formed from lactose, maltose and the corresponding bionic acids. The most peculiar aspect of this oxidation is its site in the molecule. It might be expected that the oxidation would occur in the aglycone part of the disaccharide, particularly in the case of bionic acids, with the formation of 2- or 5-ketobionates. However, oxidation takes place on the $\mathrm{C}_{3}$ of the glycosyl portion. These compounds constitute the first examples of 3-ketosugar derivatives isolated as intermediates in a metabolic pathway. The chemistry of these compounds is barely known. We are only aware of the existence of methyl- $\beta$-3-keto-D-glucopyranoside, obtained through dichromate oxidation from methyl- $\beta$-D-glucopyranoside (Lindberg \& Theander, 1954). Some of our results have been published in a short 
communication (Bernaerts \& De Ley, 1958). In the present paper we describe the method used for the microbiological production of the new compounds, as well as a procedure for obtaining them in a chromatographically pure state.

\section{METHODS}

Organisms used. Two active strains of bacteria were isolated from Petri plates on a medium containing $2 \%(w / v)$ agar, mineral salts, $0 \cdot 1 \%(w / v)$ yeast extract and $2 \%(w / v)$ lacto- or maltobionate as main carbon source, which had been inoculated with river water. The two strains were nearly identical. They grew very well on either bionate, on the corresponding disaccharides and on other carbohydrates. They have been maintained in our laboratory for several years on a simple mineral medium with glucose as the main carbon source. No notable loss of the oxidizing properties has been observed during this period.

These strains displayed most of the characteristics of Alcaligenes faecalis, as described in Bergey's Manual (6th edition). However, their pronounced saccharolytic properties set them apart from the species in this genus, which have only feeble power of attacking carbohydrates. The real taxonomic position of our strains is still under investigation. Authentic strains of $\boldsymbol{A}$. faecalis grew poorly on the disaccharides or the bionic acids and did not possess the oxidative properties to be described.

Detection of 3-ketoglycosides. 3-Ketoglycosides in the culture media were easily detected by virtue of their property of reducing Fehling, Scales and other sugar reagents at room temperature. This reduction occurred suddenly a few seconds to some minutes after a sample of the culture medium had been mixed with the reagent. The relative amounts of the strongly reducing compounds present could be roughly estimated by two procedures: either by titration of the $\mathrm{Cu}_{2} \mathrm{O}$ formed from the Scales reagent after $2 \mathrm{hr}$. at room temperature, or by determining the 'reduction time'. The latter value is the time required for a mixture of equal volumes of culture medium and Scales reagent to turn yellow. The more reducing material present, the faster this reduction takes place. One can use either one of these methods to follow the production of the strongly reducing compounds during the aerobic fermentation. However, they do not allow a quantitative estimation of the yield.

The method of Lanning \& Cohen (1951) for the quantitative estimation of 2-ketohexonic acids was also used. Our compounds reacted with o-phenylenediamine $\mathrm{HCl}$, after heating for $30 \mathrm{~min}$. in a boiling water bath. The oxidation products from malto- and lactobionate gave derivatives with a maximum absorption at $350 \mathrm{~m} \mu$, those from lactose and maltose at $335 \mathrm{~m} \mu$. 3-Ketogalactosyl-glucoside (100 $\mu$ g.) gave an optical density of 0.825 at $335 \mathrm{~m} \mu$, as measured in the Beckman spectrophotometer, model DU.

Paper chromatography. A large number of solvents commonly used in the paper chromatography of sugars were tried for the purification of our compounds. Most of these solvents did not allow the separation of the substrate from the oxidation products, with the exception of water-saturated phenol (solvent A) 
and a mixture of ethyl acetate, pyridine, acetic acid and water $(5+5+1+3$; solvent B). Solvent A separated lactose and maltose from their oxidation products. The $R_{F}$ values were 0.50 for the oxidation product from maltose and $\mathbf{0 . 1 8}$ for the oxidation product from lactose; the $R_{F}$ value for both substrates was $\mathbf{0 . 8 8}$.

The oxidation product from maltobionate was separated from the corresponding substrate with solvent $B$. The $R_{F}$ values were approximately $\mathbf{0 . 2 4}$ for the substrate and 0.34 for the oxidation product. A satisfactory separation of lactobionate from its oxidation product was only obtained with solvent $\mathbf{A}$ after conversion into the lactones by boiling a $5 \%$ solution of the mixture in $0.75 \mathrm{~N}-\mathrm{HCl}$ for $3 \mathrm{~min}$. The excess of $\mathrm{HCl}$, which prevented a good separation, was partially eliminated by neutralization to $\mathrm{pH} 2 \cdot 5$ with weak anion exchangers (Merck II). Complete neutralization was avoided to prevent lactone ring opening. The $\boldsymbol{R}_{\boldsymbol{F}}$ values were approximately $\mathbf{0 . 2 7}$ for the lactone of lactobionate and $0 \cdot 15$ for the lactone of its oxidation product.

Many spray reagents for sugars could be used to reveal the spots of the oxidation products. One of the most specific was o-phenylenediamine $\mathbf{H C l}$ (Lanning \& Cohen, 1951) which gave a typical blue colour. No other compound tested showed this colour except methyl- $\beta$-3-keto-D-glucopyranoside. The lactones were located according to Abdel-Akher \& Smith (1951). The bionates were located after successive sprayings with $\mathrm{AgNO}_{3}$ and $\mathrm{NaOH}$.

Calcium lacto- and maltobionates were prepared by means of electrolytic oxidation according to Isbell \& Frush (1931). The potassium salt was obtained by neutralization with KOH after removal of calcium by oxalic acid.

Preparation of autolysed bacteria. The bacteria were grown for $20 \mathrm{hr}$. in a medium containing $(\%, w / v): 0.2,\left(\mathrm{NH}_{4}\right)_{2} \mathrm{SO}_{4} ; 0 \cdot 1, \mathrm{KH}_{2} \mathrm{PO}_{4} ; 0.025, \mathrm{MgSO}_{4}$. $7 \mathrm{H}_{2} \mathrm{O} ; 0 \cdot 175$, yeast extract (Difco); and 1 , lactose, maltose or a bionate; finally adjusted to $\mathrm{pH} 6 \cdot 8$.

The bacteria were centrifuged down and washed twice with physiological saline. The bacterial paste contained c. $15 \%$ dry matter; $0.75 \mathrm{ml} .0 .05 \mathrm{M}$ phosphate buffer (pH 7.0), 0.125 ml. ethyl acetate and $0.025 \mathrm{ml}$. toluene were added to each gram of this paste. The suspension was kept overnight at $20^{\circ}$ and used the next day for the estimation of the hydrolase activity. Glassware and solutions were sterilized before use; Kluyver \& Custers (1940) observed that contamination is possible even under toluene.

Determination of hydrolase activity. To $1 \mathrm{ml}$. autolysed bacteria were added $19 \mathrm{ml}$. of $0.21 \%(\mathrm{w} / \mathrm{v})$ substrate dissolved in $0.005 \mathrm{M}$-phosphate buffer. Control experiments with the same quantity of phosphate buffer were included. The mixtures were incubated in a water bath at $30^{\circ}$, samples of $0.5 \mathrm{ml}$. or less were taken at regular intervals and made up to $1 \mathrm{ml}$. with $0.005 \mathrm{~m}$ phosphate buffer. To determine the rate of monose formation from lactose and maltose, the method used was as described previously (Bernaerts \& De Ley 1957). However, no precipitation occurred by the addition of the copper salt, as in the case with autolysed cells from Corynebacterium simplex. The proteins could not be removed by some other method without introducing foreign ion interference. Although the solution was slightly turbid, the changes in colour 
intensity could be measured in the colorimeter with a satisfactory accuracy. The optical transmission was read with reference to a sample of the same volume taken in control experiments in which the quantity of substrate and phosphate, present in the sample, was added after the copper reagent. These readings were converted into percentage of the hydrolysed substrate by means of a series of reference curves, one for each initial concentration of substrate. The method, as described here, was not sufficiently sensitive to follow the hydrolysis of malto- and lactobionate. Therefore, the modification of the Scales method by Isbell, Pigman \& Frush (1940) was used.

\section{RESULTS}

\section{Formation of the oxidation products by growing bacteria}

The active strains grew very well on lactose, maltose, the corresponding bionates and on different monoses. No growth was observed under anaerobic conditions. The optimal temperature for the formation of the oxidation products by growing bacteria in strongly aerated media was about $35^{\circ}$.

The media contained $(\%, w / v): 0.2,\left(\mathrm{NH}_{4}\right)_{2} \mathrm{SO}_{4} ; 0.1, \mathrm{KH}_{2} \mathrm{PO}_{4} ; 0.025$, $\mathrm{MgSO}_{4} .7 \mathrm{H}_{2} \mathrm{O} ; 0 \cdot 175$, yeast extract (Difco); and 4, of a disaccharide or potassium bionate. The minerals and the yeast extract were dissolved in half of the required volume of tap water. The solution was adjusted to $\mathrm{pH} 6.8$ and autoclaved. The carbohydrate was dissolved in the other half of the volume and sterilized by filtration. The two solutions were mixed aseptically and about $1 \%(w / v)$ sterilized $\mathrm{CaCO}_{3}$ was added. The medium was distributed in shallow layers in Fernbach flasks, heavily inoculated with a suspension of young organisms and incubated in a shaking device at $35^{\circ}$. Strong aeration and heavy inoculation were required for a good yield of 3-ketoglycosides. Samples were withdrawn aseptically at regular intervals and analysed for 8-ketoglycosides.

The results of a series of experiments are illustrated in Fig. 1. The formation of the strongly reducing substances followed the same pattern as described for other intermediates in oxidative processes, namely, they reached a maximum after a few days and then slowly disappeared. In the particular experiment illustrated the maximum was reached after 2 days, although in most cases the maximum was obtained after 1 day. It was shown by paper chromatography that all the substrate was not yet consumed. Not even traces of the 3-ketoglycosides were detected in media containing glucose, galactose, gluconate or equimolar mixtures of glucose + galactose, glucose + gluconate, galactose +gluconate. This showed that the strongly reducing substances were formed before the oxygen bridge in either the disaccharides or the bionates was broken by hydrolysis. About $75 \%$ of the total amount of lactose was converted into the corresponding 3-ketoglycoside. In the experiment reported in Fig. 1, no appreciable amounts of the strongly reducing substances were produced in the maltose media. In other experiments higher yields were obtained, when a very heavy inoculum was used and the flasks were vigorously shaken.

Paper chromatography of the culture media showed that each substrate 
gave rise to only one type of reducing compound (with all solvents only one spot was revealed), that the oxidation products were slightly different from each other according to the substrate used and yet that their properties were very similar (the colours obtained with several spray reagents were identical). The full results on the chemical properties of these compounds are published in the following paper (Bernaerts \& De Ley).

After a few days of incubation the media displayed a varying viscosity, depending on the carbohydrate used, which was probably an indication of the amount of polysaccharides formed. Disaccharides and monoses yielded the most viscous media; with bionates they were less so.

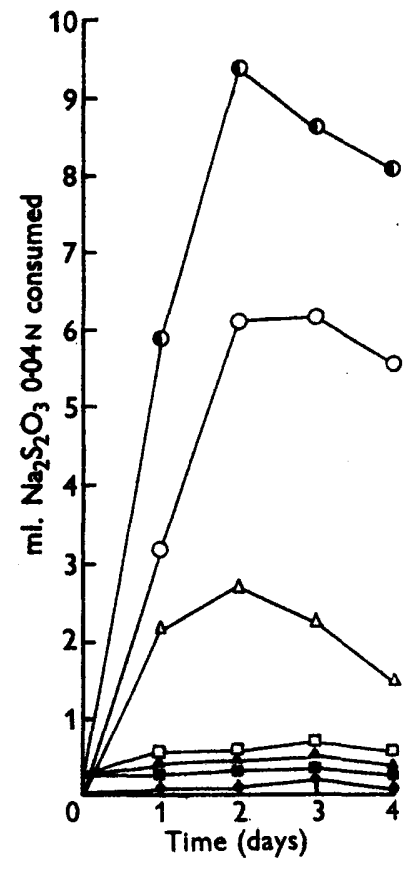

Fig. 1

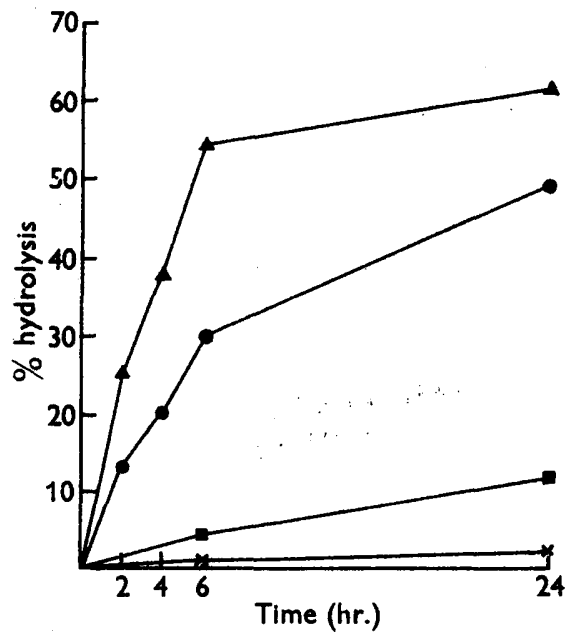

Fig. 2

Fig. 1. Formation of the strongly reducing substances by growing organisms from different substrates: lactobionate $(D-D)$, lactose $(O-O)$, maltobionate $(\Delta-\Delta)$, maltose $(\square-\square)$, galactose $(\Delta-\Delta)$, glucose $(\square-\square)$, gluconate $(0-0)$. Each curve was obtained by titrating the $\mathrm{Cu}_{2} \mathrm{O}$ formed (ml. $\mathrm{Na}_{2} \mathrm{~S}_{2} \mathrm{O}_{3}, 0.04 \mathrm{~N}$ ) in the Scales method, after $2 \mathrm{hr}$, contact of $2 \mathrm{ml}$. centrifuged culture medium with $10 \mathrm{ml}$. copper reagent.

Fig. 2. Hydrolysis of maltose $(\Delta-\Delta)$, lactose $(-O)$, lactobionate $\left({ }^{-}-D\right)$ and maltobionate $(x-x)$ by autolysed bacteria. For conditions, see text.

\section{Purification of the oxidation products}

Solid materials were eliminated from the cultures by centrifugation. The opalescent supernatant fluid was treated with equal volumes of $0 \cdot 1 \mathrm{M}-\mathrm{K}_{\mathbf{a}} \mathrm{Fe}$ $(\mathrm{CN})_{6} \cdot 8 \mathrm{H}_{2} \mathrm{O}$ and $0 \cdot 2 \mathrm{~m}-\mathrm{ZnSO}_{4} \cdot 10 \mathrm{H}_{2} \mathrm{O}$ until all protein was precipitated. The cations were adsorbed by shaking with about $10 \%(v / v)$ strong cation 
exchangers (Merck I or Amberite IR 120). The further procedure for the purification of the disaccharide media was different from that for the bionate media.

The resulting acid solutions, containing the oxidation products from lactose and maltose, were neutralized with weak anion exchangers (e.g. Merck II). The clear and colourless solutions were concentrated by lyophilization. The oxidation products were purified and freed from the last traces of substrate by paper chromatography. A $10 \%(w / v)$ solution was applied in narrow bands on a series of large sheets of Whatman no. 1 paper and developed as an ascending chromatogram with solvent $\mathrm{A}$. The band with the oxidation product was located with $o$-phenylenediamine $\mathrm{HCl}$, cut out, dried at room temperature and the phenol eliminated by a stream of water vapour. The strips were eluted with water and the solution lyophilized.

Anion exchangers were unsuitable for the purification of the bionate media, because the oxidation products remained partially adsorbed. Therefore, sulphates and phosphates were precipitated with $\mathrm{Ba}(\mathrm{OH})_{2}$; an alkaline $\mathrm{pH}$ was avoided. In order to obtain a cleaner separation of the oxidation product from the lactobionate, the acids were converted into the lactones by boiling for $3 \mathrm{~min}$. in $0.75 \mathrm{~N}-\mathrm{HCl}$. Paper chromatographic separation was carried out as described above. The lactone of the oxidation product was eluted, but traces of $\mathrm{HCl}$ still remained. The lactone was converted into the salt by neutralization.

The separation of the lactone of the oxidation product from maltobionate and its substrate was unsatisfactory with all the solvents used. The separation in the salt form was effected with solvent $B$.

The amounts of the oxidation products from the bionates, obtainable by this chromatographic procedure, were rather small, because the separation of the oxidation product of the bionates from their substrates is not so clean as in the case with the corresponding disaccharides. All attempts to obtain crystalline oxidation products failed. Only colourless to yellowish syrups in a chromatographically pure state were obtained.

\section{Hydrolysis of disaccharides and bionates by autolysed bacteria}

Since maltose gave a considerably smaller yield of oxidation products than lactose, and the disaccharides were worse sources than the corresponding bionates, it was considered interesting to verify the correlation between the hydrolase activity and the formation of the oxidation products. The results of one experiment are represented in Fig. 2. The hydrolysis of the disaccharides proceeded much faster than that of the corresponding bionates, which tallies with the specificity of the $\alpha$-glucosidases and $\beta$-galactosidases, reported by Pigman (1944). However, the ratio of the hydrolysis velocities of lactose and lactobionate by enzyme preparations of our strains are different from the results reported for the $\beta$-galactosidase of either sweet almond (Helferich, Pigman \& Isbell, 1939) or Corynebacterium simplex (Bernaerts \& De Ley, 1957). Maltose was hydrolysed about twice as fast as lactose. The bionates were attacked only slowly. 


\section{DISCUSSION}

The formation of 8-ketoglycosides by the action of micro-organisms on disaccharides has not been described before; in fact, these compounds were hitherto unknown. This discovery discloses a new pathway of disaccharide catabolism by micro-organisms, in addition to the four types already known, namely hydrolysis, transfer, phosphorolysis and oxidation of the aldehyde group. The interesting aspect of the formation of these 3-ketoglycosides is that the substrate molecules are oxidized before the splitting of the oxygen bridge.

In our bacteria two mechanisms apparently compete for the substrates, namely, hydrolysis and oxidation. The stronger the hydrolase activity, the smaller the yield of the oxidation products. The former pathway is particularly important for maltose, explaining the small amounts of 3-ketoglucosylglucose formed. Maltobionate is much more difficult to hydrolyse by the $\alpha$-glycosidase, thus a higher yield of 3-ketoglucosyl-gluconate is obtained. The same reasoning applies to lactose and lactobionate. $\mathbf{A}$ third factor, which probably still enters the competition and whose importance is difficult to assess in quantitative terms, is the formation of the supposed polysaccharides, responsible for the viscous media.

We extend here our sincere thanks to Dr La Rivière (Laboratory for Microbiology, Technical University, Delft, Holland) for supplying authentic strains of Alcaligenes faecalis, and to Dr B. Lindberg (Stockholm) for the gift of a sample of methyl- $\beta$-3keto-D-glucopyranoside.

One of us (J. De L.) is an Associé du Fonds National de la Recherche Scientifique (Belgium).

\section{REFERENCES}

Abdel-Akrer, M. \& Smith, F. (1951). The detection of carbohydrate esters and lactones after separation by paper chromatography. J. Amer. chem. Soc. 73, 5859 .

Bernaerts, M. J. \& De Ley, J. (1957). The catabolism of lactose and lactobionate by Corynebacterium simplex. Leeurvenhoek. ned. Tijdschr. 23, 333.

Bernaerts, M. J. \& De Ley, J. (1958). 3-Ketoglycosides, new intermediates in the bacterial catabolism of disaccharides. Biochim. biophys. Acta, 30, 661 .

EdDy, B. P. (1958). Bacterial oxidation of lactose and melibiose. Nature, Lond. $181,904$.

Helferich, B., Pigman, W. \& Isbell, H. S. (1939). Die Spaltbarkeit von Lactobionsäure durch Süssmandel-emulsin. Z. physiol. Chem. 261, 189.

Isbell, H. S. \& Frush, H. L. (1931). The oxidation of sugars. 1. The electrolytic oxidation of aldoses in the presence of a bromide and calcium carbonate. J. Res. nat. Bur. Stand. 6, 1145.

Isbell, H. S., Pigman, W. \& Frush, H. L. (1940). Reducing powers of various sugars with alkaline copper-citrate reagent. J. Res. nat. Bur. Stand. 24. 241.

KIUYvER, A. J. \& Custers, M. (1940). The suitability of disaccharides as respiration and assimilation substrates for yeasts which do not ferment sugars. Leeurvenhoek ned. Tijdschr. 6, 121.

KuUYver, A. J., De Ley, J. \& RiJven, A. (1951). The formation and consumption of lactobionic and maltobionic acids by Pseudomonas species. Leeurvenhoek ned. Tijdschr. 17, 1. 
Lanning, M. C. \& Coman, S. S. (1951). The detection and estimation of 2-ketohexonic acids. J. biol. Chem. 189, 109.

Lindmerg, B. \& Thrander, O. (1954). The oxidation of glycosides. IV. Oxidation of methyl- $\beta$-D-glucoside with dichromate. Acta chem. scand. 8, 1870.

Prgman, W. (1944). Specificity, classiflation, and mechanism of action of the glycosidases. Advanc. Enzymol. 4, 41.

Stopora, F. H. \& Lockwood, L. B. (1947). The oxidation of lactose and maltose to bionic acids by Pseudomonas. J. biol. Chem. 171, 213.

(Received 6 July 1959) 